\title{
Ni/Si-BASED CONTACTS TO GaN: THERMALLY ACTIVATED STRUCTURAL TRANSFORMATIONS LEADING TO OHMIC BEHAVIOR
}

E.Kaminska $^{\text {a) }}$, A.Piotrowska ${ }^{\text {a) }}$, J.Jasinski ${ }^{\text {b) }}$, J.Kozubowski ${ }^{\text {c) }}$, A. Barcz ${ }^{\text {a) }}$, K.Golaszewska $^{\text {a) }}$, D.B.Thomson $^{\text {d) }}$, R.F.Davis ${ }^{\text {d) }}$, M.D.Bremser ${ }^{\mathrm{e}}$.

${ }^{a}$ Institute of Electron Technology, Al.Lotnikow 46, Warsaw, Poland, eliana@ite.waw.pl.

${ }^{b)}$ Institute of Experimental Physics, Warsaw University, Warsaw, Poland

${ }^{c}$ Faculty of Material Science and Eng., Warsaw Technical University, Warsaw, Poland

${ }^{d)}$ Department of Material Science and Eng., NCSU, Raleigh, NC 27695-7907, USA

${ }^{\text {e) }}$ Aixtron, Inc., Buffalo Grove, IL 60089, USA

Cite this article as: MRS Internet J. Nitride Semicond. Res. 4S1, G9.9

\begin{abstract}
Structural transformations in Ni/Si-based contacts to $\mathrm{GaN}$ occurring under heat treatment have been studied using transmission electron microscopy and secondary ion mass spectrometry. Transition from non-ohmic to ohmic behavior correlates with reaction between $\mathrm{Ni}$ and $\mathrm{Si}$, and decomposition of the initially formed interfacial Ni:Ga:N layer. Transport of dopant atoms from metallization into GaN testifies in favour of the SPR process of ohmic contact formation
\end{abstract}

\section{INTRODUCTION}

One of the key problems in GaN-based devices is a poor quality of ohmic contacts to p$\mathrm{GaN}$. The commonly adopted procedure for making ohmic contacts involves the use of highwork-function metallization schemes. These contacts convert from Schottky to ohmic-like after annealing, yielding resistivities of about $10^{-2} \Omega \mathrm{cm}^{2}$ [1].

In order to reduce the contact resistivity, procedures enhancing the concentration of the active dopant in the semiconductor superficial region should be considered. To achieve that, we have adopted the idea of Sands et al. [2] of the incorporation of a dopant into the subcontact region by solid-state dissolution and subsequent regrowth (SPR). We have used $\mathrm{Ni} / \mathrm{Si}$ metallization, with $\mathrm{Mg}$ as a dopant to produce contacts to $\mathrm{p}-\mathrm{GaN}$. For n-GaN, Si was the intended donor dopant. It has been shown that these contacts became ohmic after annealing at temperatures ranging from 400 to $600^{\circ} \mathrm{C}$, with resistivity of $\sim 1 * 10^{-3} \Omega \mathrm{cm}^{2}$ on p-type $\mathrm{GaN}$ with hole concentration $3 * 10^{17} \mathrm{~cm}^{-3}[3]$.

In order to further elucidate structural changes that take place during the formation of ohmic contacts, a study of the microstructure of $\mathrm{Ni} / \mathrm{Si}$-based contacts has been performed. We have used transmission electron microscopy (TEM) methods and SIMS. The high spatial resolution of TEM provides details about the morphology of metal/semiconductor interfaces, phase compositions and crystallographic relationships in the contact region. SIMS was applied to probe the elemental depth profiles. The question of dissimilarities in the behavior of p-type and ntype metallizations during the formation of ohmic contacts has been of special concern.

\section{EXPERIMENTAL PROCEDURE}

Contacts under investigation have been made to (0001) oriented GaN epilayers, 1-2 $\mu \mathrm{m}$ thick, grown via organometallic vapour phase epitaxy on AlN buffer layers predeposited on $6 \mathrm{H}-$ 
$\mathrm{SiC}$ substrates [4]. Prior to metal deposition, the samples were etched in buffered $\mathrm{HF}$ and in $\mathrm{NH}_{4} \mathrm{OH}: \mathrm{H}_{2} \mathrm{O}$ (1:10). The cleaning was finished in the deposition chamber by heat treatment at $400^{\circ} \mathrm{C}$ for $10 \mathrm{~min}$., under UHV conditions, for thermal desorption of hydrocarbon contaminants. The metallization in the form of sandwich structures $\mathrm{Ni} / \mathrm{Mg} / \mathrm{Ni} / \mathrm{Si}$ and $\mathrm{Ni} / \mathrm{Si} / \mathrm{Ni} / \mathrm{Si}$ for $\mathrm{p}$ - and $n$ type GaN, respectively, was deposited by e-beam evaporation. The thickness of consecutive metallization films was $25 \mathrm{~nm} / 8 \mathrm{~nm} / 25 \mathrm{~nm} / 240 \mathrm{~nm}$.

In view of a high thermal stability of $\mathrm{GaN}$, contacts were fabricated in a two-step process. The first layer of nickel was evaporated onto the substrate held at $350^{\circ} \mathrm{C}$, then the sample was cooled down to room temperature, and the deposition of the metallization was completed. Finally, heat treatment was carried out in flowing $\mathrm{N}_{2}$, at temperatures $200-400^{\circ} \mathrm{C}$ for $30 \mathrm{~min}$.

The microstructure of contacts was investigated by cross-sectional transmission electron microscopy (XTEM) and high resolution imaging (HREM) combined with energy dispersive x-ray spectroscopy (EDX). TEM observations were performed using a JEOL JEM 3010 microscope operating at $300 \mathrm{keV}$. A microprobe beam size of $\sim 10 \mathrm{~nm}$ was used for EDX analysis.

SIMS profiling was performed in a Cameca $6 \mathrm{~F}$ instrument with a caesium primary ion beam and detection of $\mathrm{CsM}_{\mathrm{i}}^{+}$secondary cluster ions, which enabled the analysis with reduced matrix effects. To follow the thermally activated displacement of nickel and magnesium atoms relative to the contact interface in contacts to $\mathrm{p}-\mathrm{GaN}$, Ni-Ga and $\mathrm{Mg}-\mathrm{Ga}$ cluster ions were analyzed as well. To examine the interaction between $\mathrm{GaN}$ and nickel in as-deposited samples, the $\mathrm{Ni}-\mathrm{Ga}-\mathrm{N}$ complex was also monitored with negative secondaries.

\section{RESULTS}

TEM micrographs of as-deposited contacts to p-and n-type GaN are presented in Fig.1(a) and Fig.2(a). Both as-deposited contacts consist of four distinct layers. In both contacts the upper $\mathrm{Si}$ layers are amorphous, and the intermediate Ni films are polycrystalline. No sign of reaction between these layers was observed.

The high resolution micrographs of metal/semiconductor interfaces are shown in Fig.1(b) and Fig.2(b). In p-type metallization, the $\mathrm{Mg}$ film is polycrystalline and, as proved by EDX analysis, accommodates some amount of $\mathrm{Ni}$, while in n-type contacts, a thin film of $\mathrm{Si}$ in-between Ni layers, is amorphous.

In both contacts the layer adjacent to GaN is very uniform, 20-25 nm thick, and crystalline in nature. Fourier transforms of the lattice fringes are consistent with a face-centred cubic phase with lattice parameter $\mathrm{a}=0.341 \mathrm{~nm}$, which, within the resolution of our measurements, suggests Ni. In our previous publication [3] we speculated on the formation of a highly textured $\mathrm{Ni}_{3} \mathrm{Ga}_{2}$ phase. This work gives evidence for the presence of nickel. Because of the small lattice expansion for the Ni-Ga and Ni-N solid solutions [5], the incorporation of a few atomic percent of $\mathrm{Ga}$ and $\mathrm{N}$ into the Ni film is below the detection limit of the applied method.

No oxide at metal/semiconductor interface was observed.

The progress of the contact reaction, as registered by SIMS, is shown in Fig.3. SIMS analysis reveals evidence for the expected interaction in as-deposited contacts between $\mathrm{Ni}$ and semiconductor. The Ni-Ga cluster peak, Fig.3.(a), and Ni-Ga-N complex, Fig.3.(b), apparently coincide with the superficial region of $\mathrm{GaN}$.

Annealing at $350^{\circ} \mathrm{C}$, which is $50^{\circ} \mathrm{C}$ below the onset of the ohmic behavior, causes migration of $\mathrm{Mg}$ towards the contact interface and movement of $\mathrm{Ni}$ in the opposite direction, Fig.3.(c). This trend is preserved after annealing at $400^{\circ} \mathrm{C}$. The concentration of $\mathrm{Mg}$ in the interfacial layer has further increased, while the position of $\mathrm{Ni}$, which now forms only one distinct layer, coincides with that of Si, Fig.3(d). 

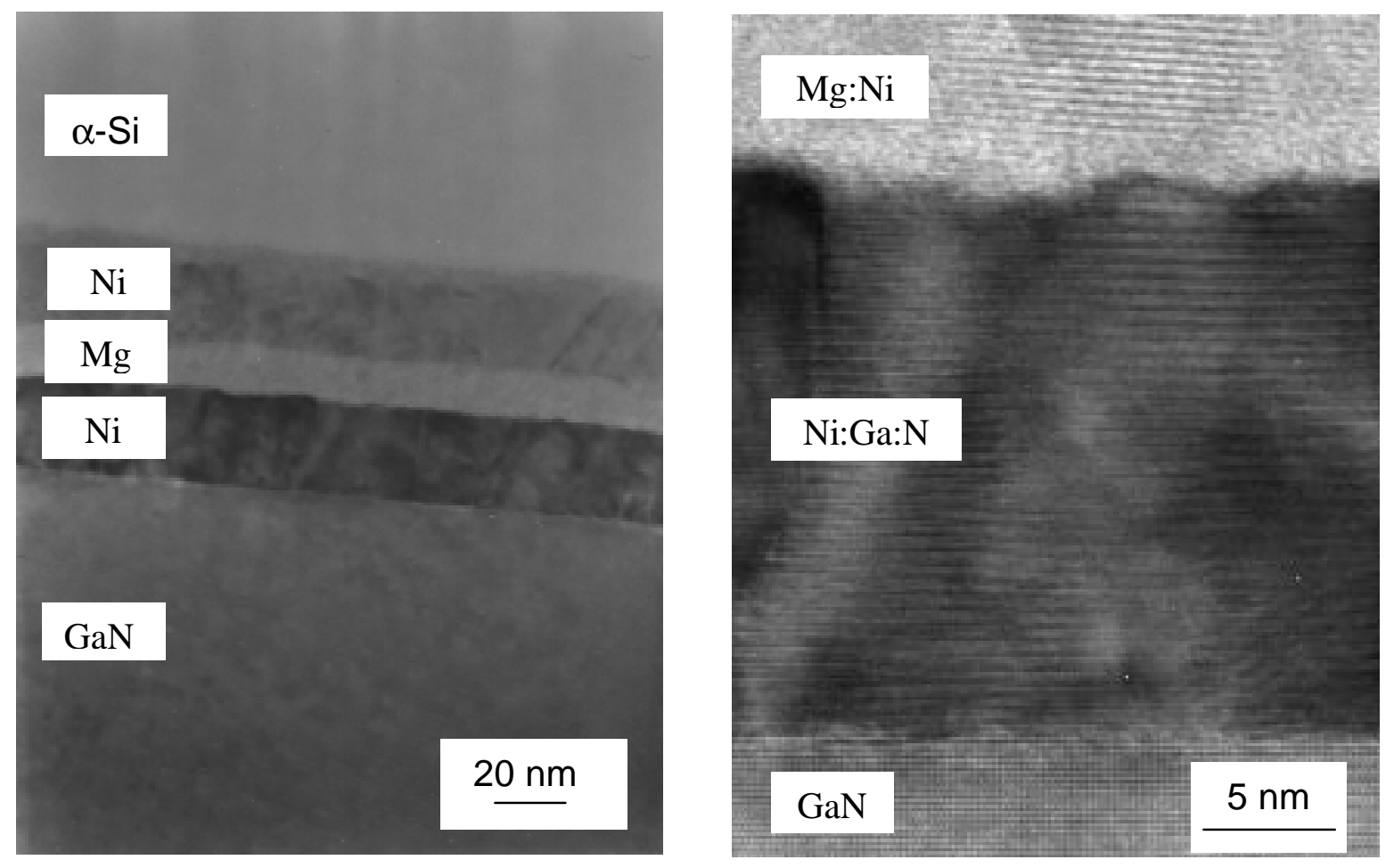

$\mathrm{c}$

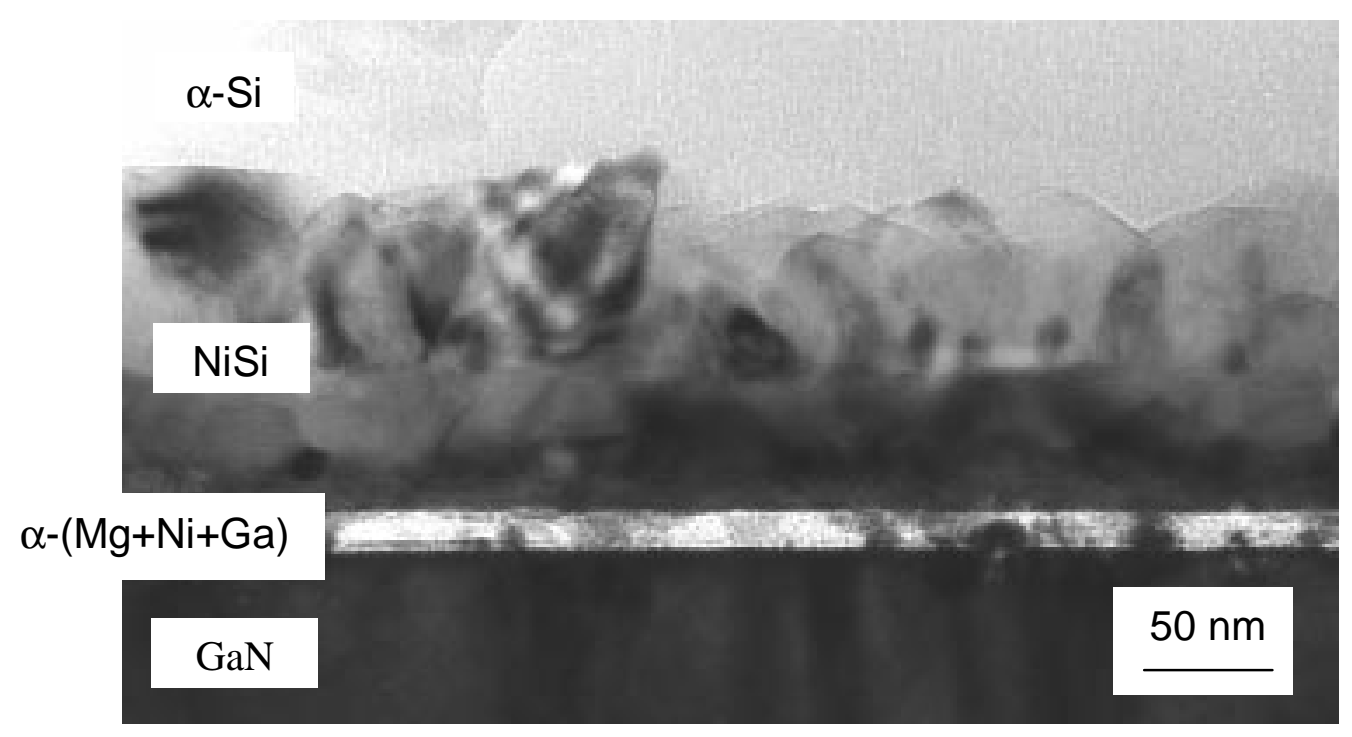

Fig. 1. XTEM micrographs of $\mathrm{p}-\mathrm{GaN} / \mathrm{Ni} / \mathrm{Mg} / \mathrm{Ni} / \mathrm{Si}$ contacts:

a) as-deposited contact, b) HREM lattice image of the interface of the as-deposited contact, c) contact annealed at $400^{\circ} \mathrm{C}$. 

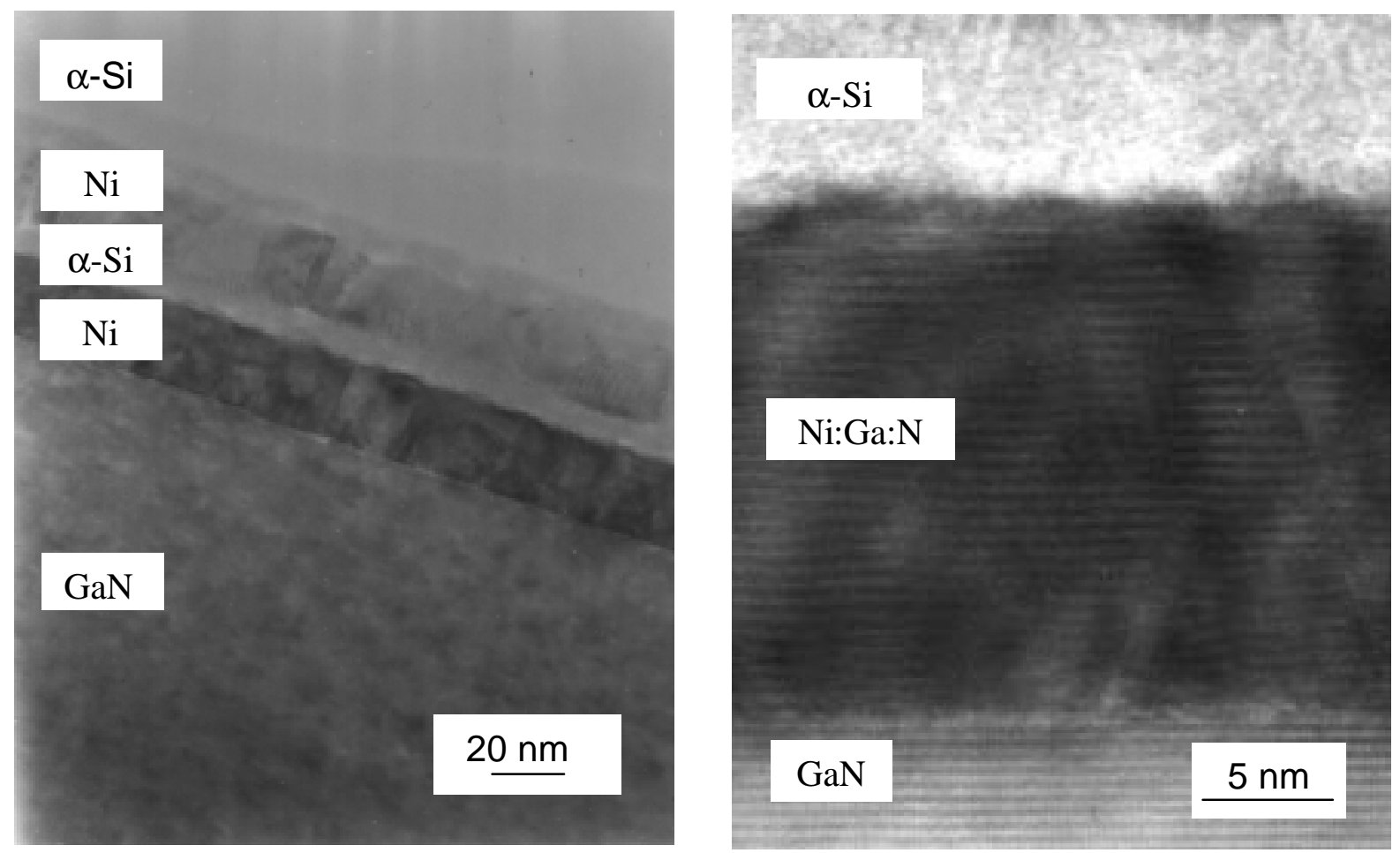

$\mathrm{c}$

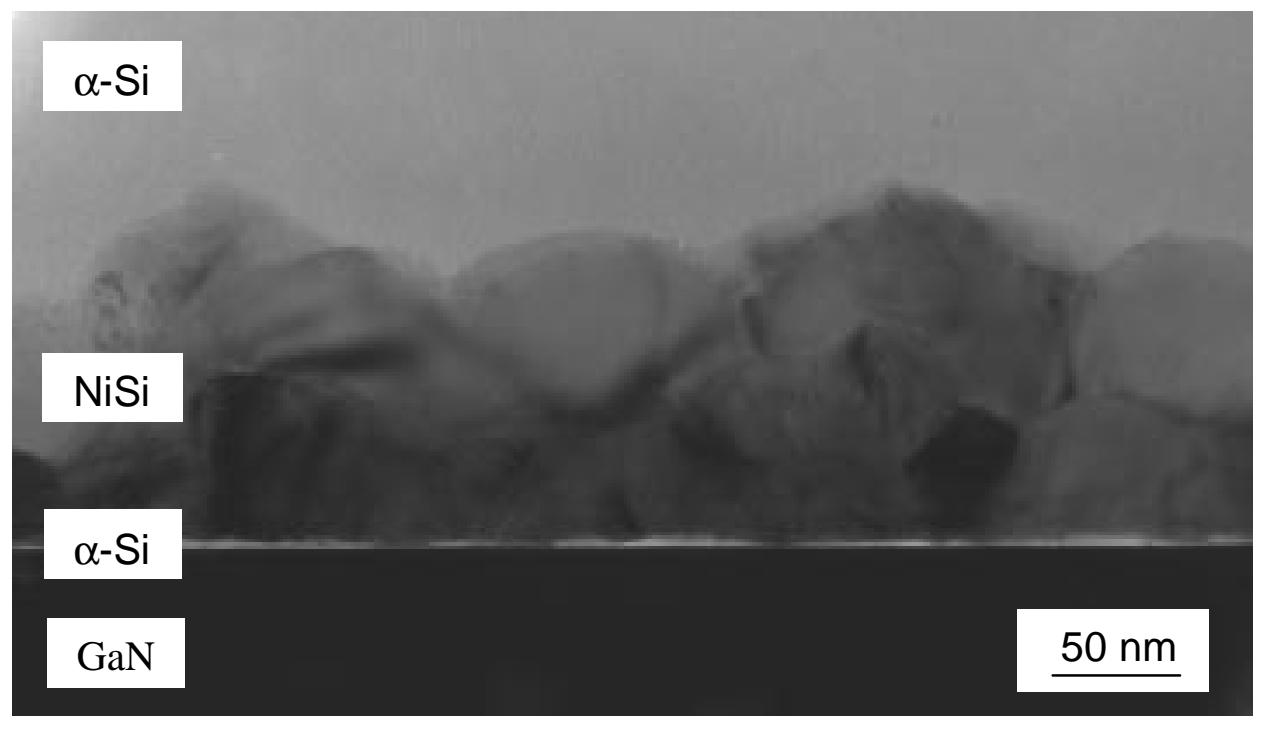

Fig. 2. XTEM micrographs of $\mathrm{n}-\mathrm{GaN} / \mathrm{Ni} / \mathrm{Si} / \mathrm{Ni} / \mathrm{Si}$ contacts:

a) as-deposited contact, b) HREM lattice image of the interface of the as-deposited contact, c) contact annealed at $400^{\circ} \mathrm{C}$. 

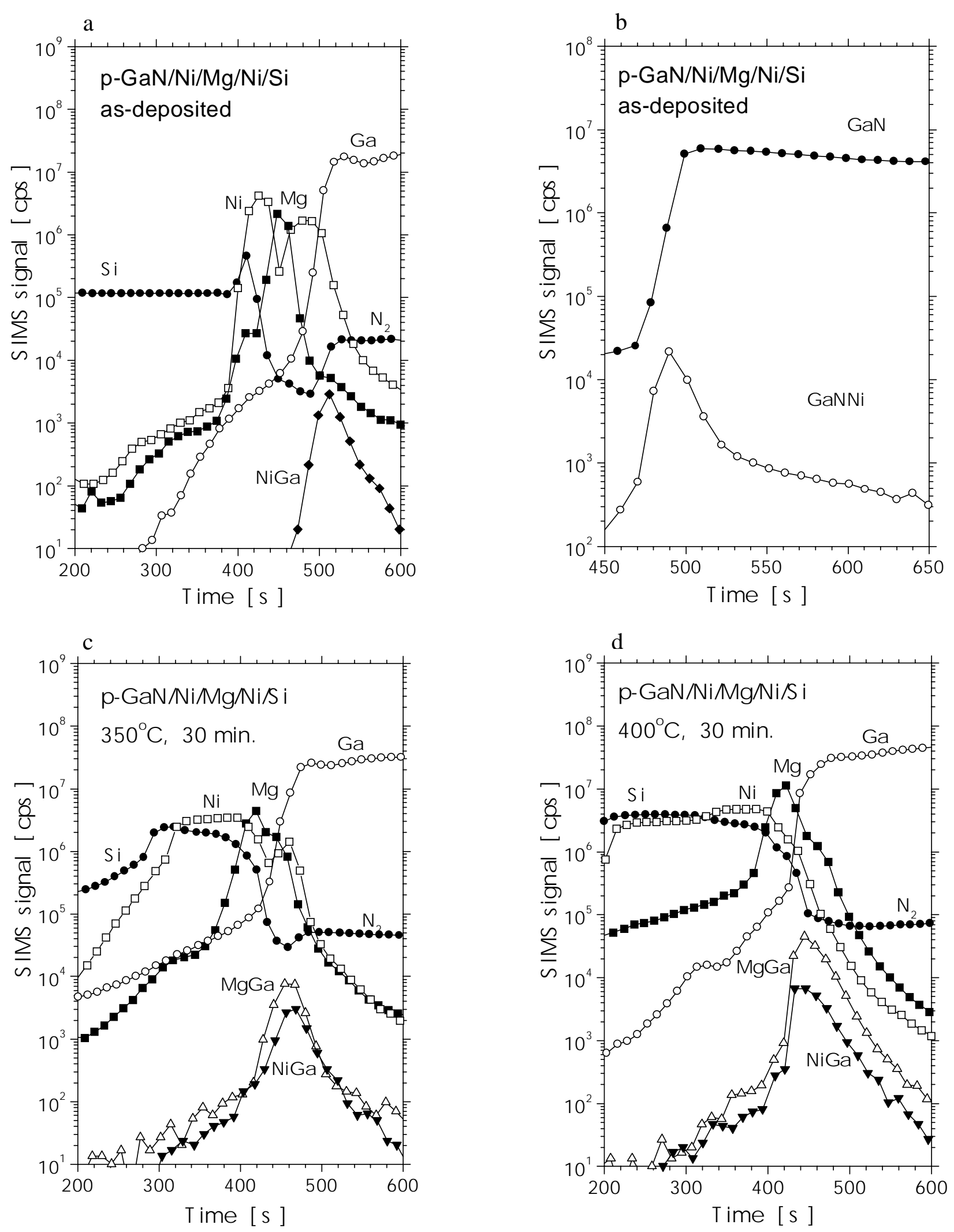

Fig. 3. SIMS in-depth profiles for $\mathrm{p}-\mathrm{GaN} / \mathrm{Ni} / \mathrm{Mg} / \mathrm{Ni} / \mathrm{Si}$ contacts:

a) and b) as-deposited contact - profiles obtained with positive and negative secondary ions, respectively, c) annealed at $350^{\circ} \mathrm{C}, \mathrm{d}$ ) annealed at $400^{\circ} \mathrm{C}$. 
The microstructures of contacts after annealing at $400^{\circ} \mathrm{C}$ for $30 \mathrm{~min}$. are presented in Fig.1(c) and Fig.2(c). In both contacts, amorphous planar interlayers, $\sim 10 \mathrm{~nm}$ thick, are formed along the interface separating the semiconductor and the metallization. Careful EDX analysis revealed that in p-type contact this layer contains $\mathrm{Mg}$, and some amount of $\mathrm{Ni}$ and $\mathrm{Ga}$. Small crystalline voids of $\mathrm{Ni}$ are present throughout this film. In the n-type contact, $\mathrm{Si}$ is the only component of the interfacial film. The main constituent of each contact consist of nickel silicide. Excess of unreacted amorphous $\mathrm{Si}$ is detected in the outermost layer. The contact interfaces are sharp and abrupt.

\section{DISCUSSION AND CONCLUSIONS}

From the experimental observations of two Ni/Si-based contacts to $\mathrm{GaN}$ some common structural transformations are apparent. During the deposition, Ni reacts with GaN and forms a highly ordered Ni layer containing some amount of Ga and $\mathrm{N}$. This reaction provides a very good oxide-free interface. Upon annealing the interfacial film decomposes, and $\mathrm{Ni}$ is transported toward the outer Si layer. At the same time, the dopant atoms ( $\mathrm{Mg}$ or $\mathrm{Si}$ ) move in the direction of the semiconductor substrate and finally form a continuous film at the interface.

As for electrical properties, the transition from non-ohmic to ohmic behavior in GaN/NiSi contact system takes place when the initial interface interlayer $\mathrm{Ni}: \mathrm{Ga}: \mathrm{N}$ decomposes as a result of $\mathrm{Si}-\mathrm{Ni}$ reaction. The NiSi phase is not in direct contact with $\mathrm{GaN}$ when the contact become ohmic, so it can not be responsible for the ohmic behavior. On the other hand, the presence of $\mathrm{Mg}$ in the superficial film of the semiconductor, in the applied temperature range, can not be explained in terms of diffusion. The contact reaction is probably accompanied by a regrowth of the decomposed volume of the semiconductor. Since the semiconductor surface layer reacted with $\mathrm{Ni}$ is very thin, the observed ohmic behavior must be due to a few monolayers thick regrown GaN film. The growth of an amorphous layer at the surface of $\mathrm{GaN}$ could lower the barrier height across the metal/semiconductor interface, and thus facilitate the formation of the low-resistance contact. The interface of $\mathrm{Ni} / \mathrm{Si}$-based contacts to $\mathrm{GaN}$ appears to be sharp as opposed to a continuous diffuse interface, characteristic of the presently used alloyed contacts. In terms of electronic properties, interface and surface morphologies, the Ni/Si contact scheme appears to be promising for device applications.

\section{ACKNOWLEDGEMENTS}

Electron Microscope JEM 3010 used in this study was founded by the Foundation for Polish Science. This work was partially supported by the Committee for Scientific Research, grant No. PBZ 28.11/P9.

\section{REFERENCES}

1. M.Murakami, Y.Koide, Critical Reviews in Solid State and Materials Science, 23, 1 (1998).

2. T.Sands, E.D.Marshall, L.C.Wang, J.Mater.Res. 3, 914 (1988).

3. E.Kaminska, A.Piotrowska, A.Barcz, M.Guziewicz, S.Kasjaniuk, M.D.Bremser, R.F.Davis, E.Dynowska, S.Kwiatkowski, Mat.Res.Soc.Symp.Proc.,vol. 482, 1077 (1998).

4. T.W.Weaks, Jr., M.D.Bremser, K.S.Ailey, E.Carlson, W.G.Perry, E.L.Piner, N.A. El-Masry, R.F.Davis, J.Mater.Res., 10, 1011 (1996).

5. M.Hansen, K.Anderko, Constitution of Binary Alloys, (McGrow-Hill Book Company, Inc.,London, 1958). 